\title{
IMPA, Instituto de Matematica Pura e Aplicada
}

Henrique Bursztyn and Roberto Imbuzeiro Oliveira (both Instituto de Matematica Pura e Aplicada, Rio de Janeiro, Brasil)

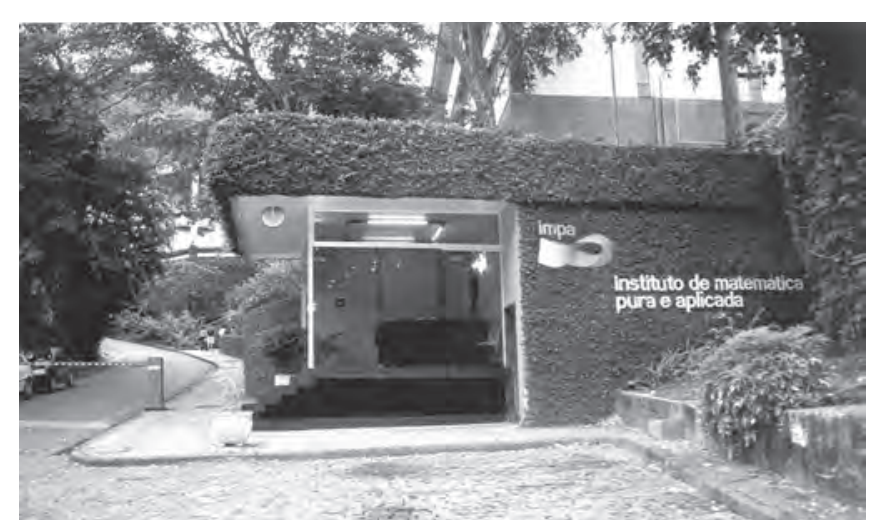

IMPA's entrance.

The "Instituto de Matemática Pura e Aplicada" (IMPA) is a research centre for mathematics situated in Rio de Janeiro, Brazil. It was created 65 years ago with the mission of pursuing high-level research in pure and applied mathematics, training new researchers and disseminating mathematics at all levels. IMPA has been pivotal in the development of mathematics in Latin America, particularly through the training of leading professionals working in the region.

The institute has recently gained wider international recognition due to the 2014 Fields Medal awarded to Artur Ávila, a former PhD student and current faculty member of the institute.

IMPA's location in the hills of the Tijuca Forest in Rio de Janeiro provides scenic and tranquil surroundings, which contrast with the vibrant and stimulating scientific environment of the institute. Every year, IMPA gathers prominent mathematicians from around the world for short- and long-term visits, offering ideal conditions for scientific collaboration.

IMPA is also a leading centre for graduate studies in Latin America. It runs a $\mathrm{PhD}$ programme in mathematics and offers a number of options for Master's degrees. The institute hosts around 150 graduate students and nearly half of them come from abroad, contributing to the cultural diversity of IMPA's atmosphere. Postdoctoral programmes have also helped attract young international talent to the institute.

IMPA plays an active role in disseminating mathematics. A significant proportion of existing Portuguese mathematical literature (used in universities throughout the Portuguese speaking world) comes from IMPA's publishing house. IMPA runs Summer programmes that have up to 700 participants and organises a dozen international conferences every year. It hosts training programmes for high school teachers and is responsible for the Mathe-

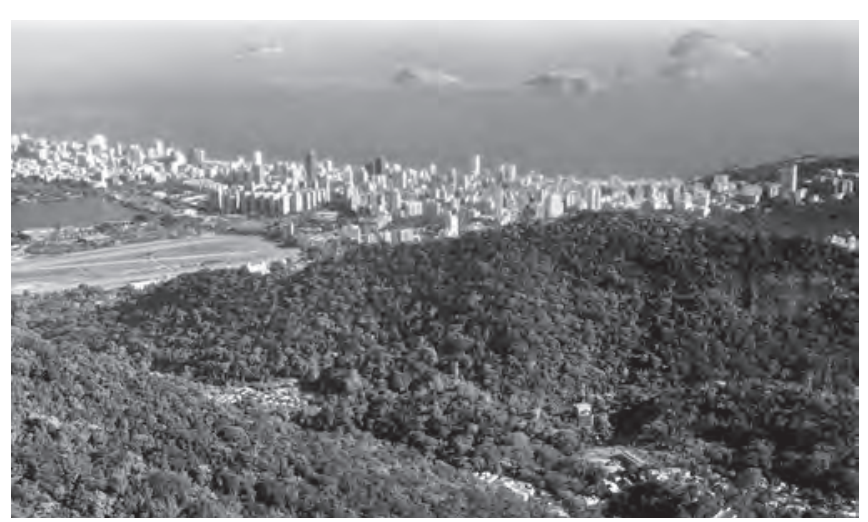

IMPA's location is in the right bottom corner of the image.

matics Olympiad for Public Schools (OBMEP), a national competition that involves 18 million pre-college children every year, discovering many new talents.

\section{Brief history}

IMPA was founded in 1952 as the first research centre affiliated with $\mathrm{CNPq}$, the Brazilian National Council for Scientific and Technological Development. The institute started with only two researchers, Leopoldo Nachbin and Mauricio Peixoto, both mathematicians of international renown at the time. A few years later, topologist Elon Lima and number-theorist Paulo Ribemboim joined IMPA's research staff.

IMPA started its activities in the premises of CBPF (Brazilian Center for Research in Physics) in Urca, Rio de Janeiro, and moved to two other locations before settling, in 1981, in its current headquarters in the forest hills above Rio de Janeiro's botanical garden.

Master's and PhD programmes at IMPA started in 1962, through a cooperation agreement with the Federal University of Rio de Janeiro. IMPA underwent a major expansion in its research activities after 1970, upon the return of a new generation of Brazilian mathematicians who had completed their PhD degrees in distinguished foreign universities. This allowed IMPA to make a qualitative leap forward and widen its research and training activities. At that time, some of the most traditional research groups at IMPA were established, such as the groups on dynamical systems and differential geometry. The growth of IMPA's scientific staff gave new impetus to its Master's and $\mathrm{PhD}$ programmes, which became internationally recognised and responsible for the training of leading mathematicians in the region.

Over the last three decades, IMPA's scientific staff have increased in number to nearly 50 researchers, covering a wide array of areas in pure and applied mathematics. 


\section{Governance and funding}

For nearly 50 years, IMPA was a public research institution under the auspices of the Brazilian Ministry of Science and Technology. This changed in 2001 when it transitioned to a new legal status as an "organização social" (OS). IMPA is now a private non-profit organisation of a special kind. Its aims and goals are specified by a contract with Brazil's Federal Government that is renewed every five years, contingent on good performance in the previous period.

The OS model has made the institute more dynamic and flexible. A streamlined hiring process has helped IMPA attract and retain talent. Institutional funding now combines private as well as public sources. Many new programmes and activities have been made feasible by the OS system. Of course, all of this has been possible only because IMPA has consistently surpassed its contractual goals.

IMPA's OS structure also specifies a governance structure with two main administrative bodies: the Board of Trustees and the Scientific Committee. The Board of Trustees supervises and regulates all of the institute's activities. It includes members of IMPA's faculty, external mathematicians, representatives from scientific societies and members from Government and society. The Scientific Committee, for its part, focuses on academic matters, such as hirings and scientific activities. It is composed of seven members from IMPA and five external members from the scientific community.

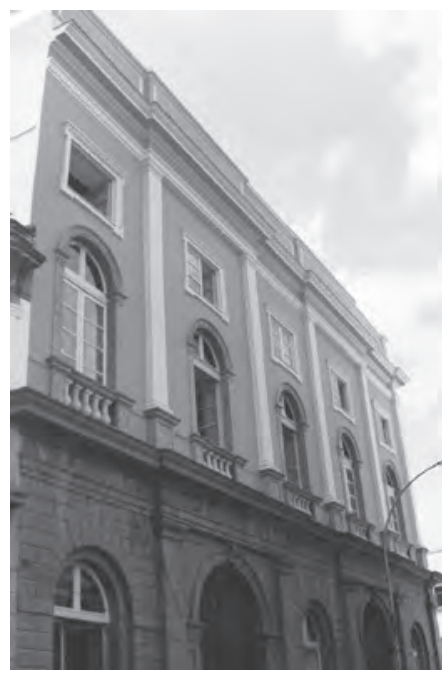

IMPA's previous facilities in downtown Rio de Janeiro. ential geometry helped propel their respective areas in South America and beyond.

IMPA's current faculty continues to play a leading role both regionally and globally. The institute has 40 regular professors (tenured and tenure-track), two special visiting professors (Etienne Ghys and Bruce Reed), two extraordinary professors (Artur Ávila and Harold Rosenberg) and five emeriti. Current research areas include: analysis and partial differential equations; algebraic geometry and representation theory; combinatorics; complex geometry and foliations; computer graphics;

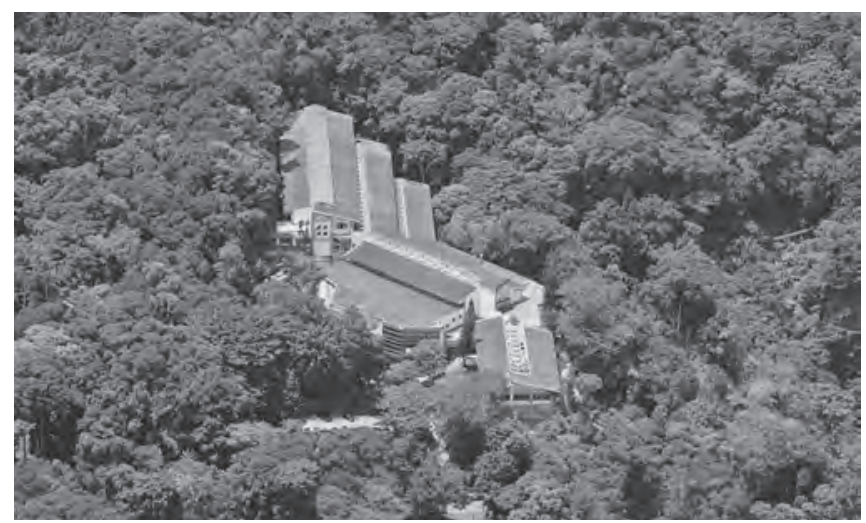

IMPA's current location.

differential and symplectic geometry; dynamical systems; fluid mechanics; mathematical economics; mathematical finance; optimisation; and probability and statistics. IMPA's high profile in worldwide research is attested by the many recent distinctions received by its professors, including Ávila's Fields Medal and four invited talks at the 2014 International Congress of Mathematicians.

IMPA's visitors and postdoctoral researchers are another major factor in making IMPA an exciting research environment. In 2016, we hosted the equivalent of 324 months of visits and postdocs. Researchers are attracted by the opportunity to collaborate with locals and other visitors in friendly, informal surroundings, with the stunning scenery of Tijuca Forest and the many attractions of Rio de Janeiro. A large number of visits to IMPA happen through cooperation agreements with international institutions, including CNRS (of which IMPA is a "Unité Mixte Internationelle"); École Normale Superieure, École Polytechnique, Brown University, Université Pierre et Marie Curie and Montréal's Centre de Recherche Mathématique.

Laboratories for applied research are another important aspect of IMPA's research life. The Fluid Dynamics Lab is devoted to fluid mechanics and its applications in the oil industry, LAMCA (the Laboratory for Mathematical Analysis in the Applied Sciences) pursues a range of projects in applied and industrial mathematics and VISGRAF is dedicated to research in computer graphics and vision.

\section{Graduate studies}

IMPA is one of Latin America's leading centres for graduate education in mathematics.

After an initial period of cooperation with the Federal University of Rio de Janeiro, IMPA's graduate programme was accredited by Brazil's Federal Council of Education in 1971 and it has been running regularly ever since. The programme has been instrumental in the development of mathematics in the region. Its alumni work in a large number of universities throughout Brazil and abroad. Through these alumni, many new centres for graduate studies have been created and consolidated around Brazil in recent years.

IMPA has granted over $450 \mathrm{PhD}$ degrees in mathematics to date, with an average of 17 new doctors per 


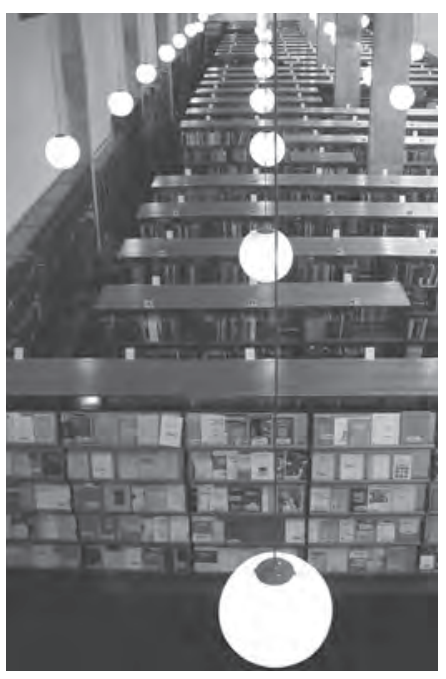

IMPA's library. year over the past 10 years. Besides its $\mathrm{PhD}$ degree in mathematics, IMPA offers four streams of academic Master's degrees: pure mathematics, mathematical economics, computational mathematics and modelling, and computer graphics. As of 2008, IMPA started a professional Master's programme on mathematical methods in finance, with a focus on quantitative finance, financial instruments and risk analysis, that is geared towards qualified professionals holding non-academic positions.

Besides receiving students from all over Brazil, IMPA's international projection has had a direct impact on the diversity of its graduate students. Currently, nearly half of the institute's students come from abroad, mostly from other countries in Latin America but also from various places in Europe, Africa and Asia. Marcelo Viana, IMPA's current director, came to the institute as a $\mathrm{PhD}$ student in the mid 1980s after completing his undergraduate degree at the University of Porto in Portugal: "I was attracted by IMPA's international reputation, especially in dynamical systems. Here I found a lively and stimulating environment, ideal for the development of my research. In time, I realised there were plenty of opportunities for extending even more the scope of my work as a mathematician. This is an institution like no other." Viana was a plenary speaker at the 1998 ICM in Berlin and is the recipient of many international prizes, most recently the Grand Prix Scientifique Louis D., one of France's most prestigious scientific awards.

Other distinguished alumni of IMPA's PhD programme include 2014 Field's Medallist Artur Ávila, who first came to the institute as a high school student, after outstanding performances in mathematics Olympiads. Avila, who completed his $\mathrm{PhD}$ degree at the age of 19, was one of many students to profit from IMPA's flexibility in absorbing and training young talents. Avila's advisor Welington de Melo was himself a PhD student at IMPA in the 1970s under Jacob Palis.

Incoming classes for IMPA's PhD programme typically number around 20 students. A similar number of students start the Master's programmes every year. All students have financial support through scholarships provided by the national funding agencies $\mathrm{CNPq}$ and Capes, as well as Rio de Janeiro's agency Faperj. Further Information on how to apply can be found at http://www. impa.br/opencms/en/ensino/index_geral/index.html.

\section{Programmes and events}

IMPA's many events and programmes are a key aspect of its contribution to mathematics at the regional and

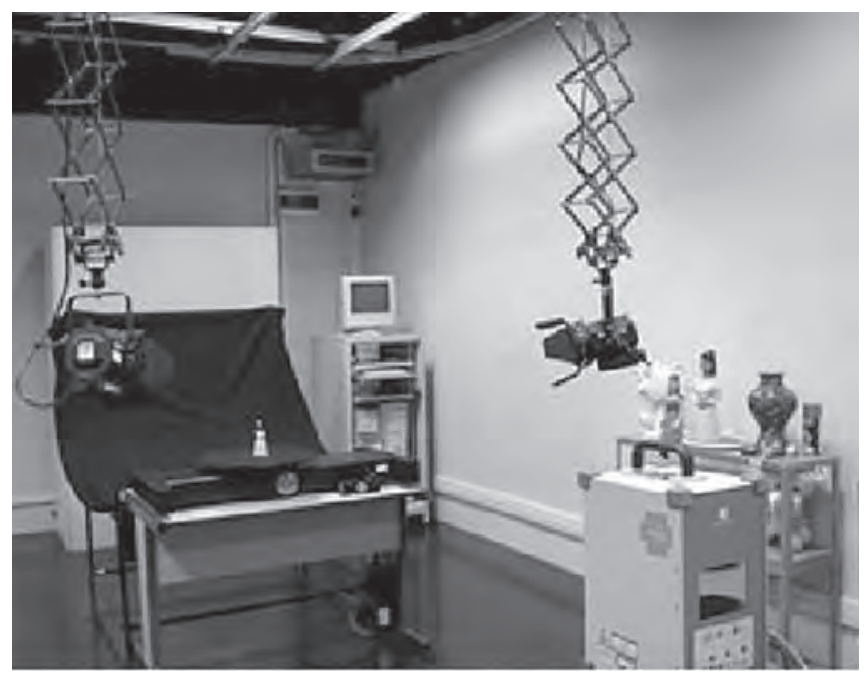

VISGRAF Lab.

global levels. In fact, it could be said that IMPA acts as a hub for mathematics in South America and (increasingly) worldwide.

The institute regularly organises 14 conferences each year. These events range from small workshops to area schools and the 1000-plus-participant Brazilian Mathematical Colloquium, which is held at IMPA every two years.

Longer thematic programmes, each lasting between two and four months, are a recent addition to the institute's roster of events. Upcoming programmes are on parameter identification in mathematical models (October-November 2017) and graph theory (January-March 2018).

Lastly, IMPA has a well known Summer Programme, during the Southern Hemisphere Summer months of January and February. The importance of this programme for South American mathematics can hardly be overstated. Each year, the programme supports between 120 and 180 undergraduates and postgraduates for intensive classes. This has had a major impact on regional mathematical culture and many of the region's best mathematicians are alumni of this school. The programme also hosts a large number of visitors at the postdoctoral and senior levels, who come to take part in seminars, watch mini-courses on cutting edge research and collaborate with local and visiting colleagues.

\section{Outreach and mathematical education}

IMPA goes well beyond its role as a premier research centre in its efforts to disseminate mathematics. Brazil's best known books for college mathematics have mainly come from IMPA's publishing house. Lecture notes from the Brazilian Mathematical Colloquium have helped promote novel research directions throughout the country. IMPA has also promoted high school mathematics through the Brazilian Mathematical Olympiad (OBM).

In recent years, IMPA has become more involved with efforts to improve pre-college mathematical education in Brazil. Early initiatives include a series of books for high school mathematics as well as the PAPMEM 
teacher recycling programme. The PROFMAT Master's programme, which trains over 2,500 teachers around Brazil, was also started by the IMPA faculty.

IMPA's best known and by far its largest activity in pre-college mathematics is the Brazilian Mathematics Olympiad for Public Schools (OBMEP). Around 18 million children register for the OBMEP competition each year. Medal awardees are eligible for special training programmes and scientific initiation scholarships when they reach college. These have provided life-changing opportunities for many of the students involved, who often come from underprivileged backgrounds.

OBMEP has also had an impact beyond the competition winners. In fact, the competitive aspect is but one facet of a multipronged initiative that includes special training programmes for teachers, freely available teaching and study materials and a series of videos on YouTube. Detailed studies have shown OBMEP's measurable impact on schools nationwide.

In 2017, OBMEP and the older Olympiad OBM will be combined into a single competition, open to private as well as public school students. This will further broaden the impact of these initiatives.

\section{The Mathematics Biennium: the ICM, the IMO and the Mathematics Festival}

The years 2017 and 2018 mark a very special time for IMPA. In 2017, the International Mathematical Olympiad will be organised in Brazil for the first time. In 2018, the International Congress of Mathematicians will be held in Rio de Janeiro, the first such event to be held in either Latin America or the Southern Hemisphere.

IMPA is proud to be deeply involved with these two activities, which are landmarks for the Brazilian mathematical community. At the same time, these landmarks should not go unnoticed by society at large. On the con- trary, the two events provide an opportunity to further promote mathematics in our country.

With this in mind, IMPA, the Brazilian Mathematical Society (SBM) and the Brazilian Academy of Sciences (ABC) approached Brazil's National Congress to make 2017 and 2018 Brazil's Mathematical Biennium. The "Joaquim Gomes de Souza" Biennium, named after Brazil's first research mathematician, was introduced into law in 2016.

The Biennium provides a boost to IMPA's dissemination efforts. This includes giving higher visibility to the ICM and the IMO and also promoting further activities. One important event is the "Festival da Matemática" in late April 2017. Hosted in Rio de Janeiro but with events nationwide, this festival features general-audience talks, movies, plays, exhibits and workshops geared toward young students and teachers. More information about the festival is available from its website (in Portuguese): http://www.festivaldamatematica.org.br/.

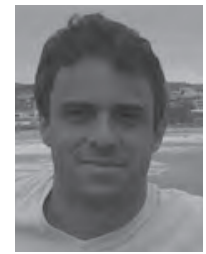

Henrique Bursztyn is a full professor at IMPA and the current head of graduate studies. His research lies in the areas of differential geometry and mathematical physics, including symplectic geometry, Poisson structures and Lie theory.

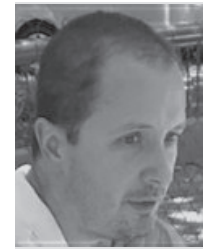

Roberto I. Oliveira is an associate professor at IMPA. He is also the current head for projects and planning at the institute. His research interests are in probability and related disciplines, such as statistics, quantum information and discrete mathematics, especially as they pertain to systems that have many degrees of freedom. 